\title{
Siew New Disease Reports \\ First report of Alternaria dumosa causing orange leaf spot disease in Iran
}

\author{
L. Fazlikhani and M.J. Soleimani*
}

Department of Plant Protection, College of Agriculture, Bu-Ali Sina University, Hamedan, Iran

*E-mail: j_soleimaniuk@yahoo.co.uk

Received: 16 Apr 2013. Published: 04 Aug 2013. Keywords: Alternariosis, Citrus aurantium

Surveys for disease in three species of wild and cultivated orange, Citrus aurantium (sour orange), C. macroptera (wild orange) and $C$. sinensis (sweet orange), were conducted in the summer of 2012.

Symptoms of foliar disease were commonly observed in several parts of Fars province. On young leaves, lesions first appeared as small brown to black spots, which soon became surrounded by yellow haloes. Lesions expanded into irregular necrotic areas that could involve large portions of the leaf (Fig. 1). To determine the causal agent of the leaf lesions, small pieces of infected tissue collected from seven different locations were surface sterilised, transferred to petri dishes containing potato dextrose agar (PDA) and incubated at $25^{\circ} \mathrm{C}$ under a $12 \mathrm{~h}$ photoperiod for 7-10 days. A dark green-olivaceous fungus with profuse golden brown, branched, and septate hyphae was consistently isolated from the infected tissue on PDA. The fungus produced conidia that were morphologically identified as an Alternaria species. For determination of microscopic characteristics, the Alternaria isolate was purified by single spore isolation and then placed on potato carrot agar (PCA) medium. Olive-brown to almost grey colonies with concentric zonation in growth developed (Fig. 2). Growth in light-exposed areas contained bushy clumps of relatively short primary conidiophores with a few short geniculate branches. Dark phase areas produced fascicles of conidiophores, usually composed of erect bundles of hyphae. Length of primary conidiophores was $60-200 \times 4-5 \mu \mathrm{m}$ with 2-3 geniculate conidiogenous sites. The conidia were brown, and mostly ovoid, 10-24 x 6-10 $\mu \mathrm{m}$ with secondary conidiophores 3-6 x $3 \mu \mathrm{m}$; and were punctuate, lacking beaks with two to three transverse septa and 1-3 longitudinal or oblique septa (Fig. 3). Long chains of conidia with 3-10 spores were sometimes branched, appearing as bushy heads.

Morphological characteristics of the colonies on PCA and V8 agar media after seven days indicated typical characteristics of Alternaria dumosa Simmons (Simmons, 1967; Simmons, 2007). The culture has been deposited in the Public Collections of the CBS, The Netherlands, with Accession No. CBS 134369.

Due to the difficulty of performing pathogenicity tests in the orchard, shoots of potted orange trees were inoculated in a greenhouse. Conidia were harvested from six-day-old cultures growing on PCA, adjusted to a suspension of $10^{6}$ conidia/ml and sprayed on young shoots and leaves of C. sinensis cv. Moro (blood orange) according to Peever et al. (1999). The inoculated shoots were kept in moistened plastic bags in the dark for two days and then in natural light at $20^{\circ} \mathrm{C}$ for two weeks. Although the method of inoculation was somehow artificial, the symptoms were similar to those observed in the orchards. Koch's postulates were satisfied after re-isolating A. dumosa from the infected tissues. The control shoots, inoculated with distilled water, remained healthy. Alternaria dumosa has been reported on citrus in the United States, Israel and Colombia (Simmons, 1999; Timmer et al., 2003) and on potato in Iran (Tahery Ardestani et al., 2010). To our knowledge this is the first report of Alternaria leaf spot on orange caused by A. dumosa in Iran. This could be a damaging disease of orange in the northern and southern areas of Iran and potentially elsewhere. However, further studies are needed on the ecology and pathogenicity of $A$. dumosa to formulate steps for controlling the leaf spot on orange.

\section{Acknowledgements}

Partial financial support for this work by the Research Council of Bu-Ali Sina University, Hamedan, Iran, is gratefully acknowledged.

\section{References}

Peever TL, Canihos Y, Olsen L, Ibañez A, Liu YC, Timmer LW, 1999. Population genetic structure and host specificity of Alternaria spp. causing brown spot of Minneola tangelo and rough lemon in Florida. Phytopathology 89, 851-860.

[http://dx.doi.org/10.1094/PHYTO.1999.89.10.851]

Simmons EG, 1967. Typification of Alternaria, Stemphylium, and Ulocladium. Mycologia 59, 67-92. [http://dx.doi.org/10.2307/3756943]

Simmons EG, 1999. Alternaria themes and variations (236-243): host-specific toxin producers. Mycotoxin 70, 325-369.

Simmons EG, 2007. Alternaria: An Identification Manual. Utrecht, Netherlands: CBS Fungal Biodiversity Centre.

Tahery Ardestani S, Sharifnabi B, Zare R, Abbasi Moghadam A, 2010. New Alternaria species associated with potato leaf spot in various potato growing region of Iran. Iranian Journal of Plant Pathology 45, 83-86.

Timmer LW, Peever TL, Solel Z, Akimitsu K, 2003. Alternaria diseases of citrus - Novel pathosystems. Phytopathologia Mediterranea 42,99-112.

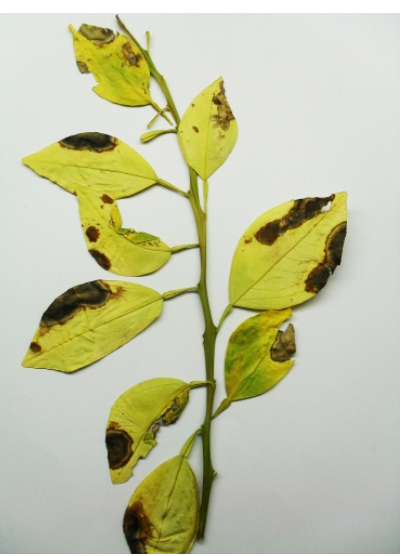

Figure 1
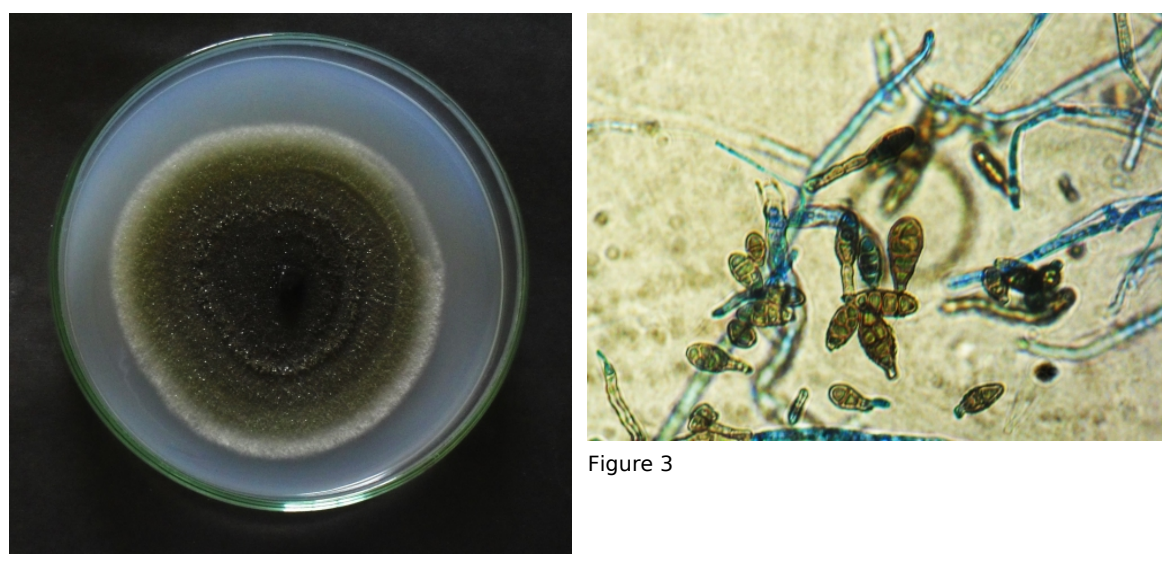

Figure 3

To cite this report: Fazlikhani L, Soleimani MJ, 2013. First report of Alternaria dumosa causing orange leaf spot disease in Iran. New Disease Reports 27, 24. [http://dx.doi.org/10.5197/j.2044-0588.2013.027.024]

(c) 2013 The Authors

This report was published on-line at www.ndrs.org.uk where high quality versions of the figures can be found. 